\title{
Exosomes in the lung cancer microenvironment: biological functions and potential use as clinical biomarkers
}

\author{
Runzhi Qi ${ }^{1 \dagger}$, Yuwei Zhao ${ }^{2 \dagger}$, Qiujun Guo ${ }^{1 \dagger}$, Xue Mi ${ }^{3 \dagger}$, Mengqi Cheng ${ }^{1}$, Wei Hou ${ }^{1}$, Honggang Zheng ${ }^{1 *}$ and \\ Baojin Hua ${ }^{1 *}$ (D)
}

\begin{abstract}
Lung cancer is one of the most common malignant tumours worldwide. however, emerging immunotherapy and targeted therapies continue to show limited efficacy. In the search for new targets for lung cancer treatment, exosomes have become a major focus of research. Exosomes play an important role in the tumour microenvironment (TME) of lung cancer and affect invasion, metastasis, and treatment responses. This review describes our current understanding of the release of exosomes derived from different cells in the TME, the effects of exosomes on T/Tregs, myeloidderived suppressor cells, tumour-associated macrophages, dendritic cells, and natural killer cells, and the role of exosomes in the endothelial-mesenchymal transition, angiogenesis, and cancer-associated fibroblasts. In particular, this review focuses on the potential clinical applications of exosomes in the lung cancer microenvironment and their prognostic and diagnostic value.
\end{abstract}

Keywords: Exosome, Lung cancer, Tumour microenvironment

\section{Background}

Lung cancer is one of the most commonly diagnosed cancer and the leading cause of cancer deaths in both sexes combined [1], despite improvements in diagnosis and treatment, such as the emergence of immune checkpoint inhibitors, new-generation drugs (e.g. EGFR-TKI, ALK, eml4), and advanced radiotherapy technology. The recurrence of non-small cell lung cancer (NSCLC) remains high, with 5-year overall survival rates ranging from $83 \%$ for stage IA to $36 \%$ for stage IIIA [2], and the 5-year survival rate for patients with small cell lung cancer (SCLC) remains fairly low at only $10 \%[3]$.

*Correspondence: zhenghonggang@gamyy.cn; huabaojin@gamyy.cn ${ }^{\dagger}$ Runzhi Qi, Yuwei Zhao, Qiujun Guo and Xue Mi contributed equally to this work

${ }^{1}$ Department of Oncology, Guang'anmen Hospital, China Academy of Chinese Medicine Sciences, Xicheng District, Beijing, China

Full list of author information is available at the end of the article
To find effective treatments and overcome low immunotherapy efficiency and drug resistance, increasing research has focused on the lung cancer microenvironment. The vasculature, immune and inflammatory cells, extracellular matrix (ECM), and cancer-associated fibroblasts (CAFs) are major components of the tumour microenvironment (TME), which is recognised as a target-rich landscape for the development of novel agents in lung cancer $[4,5]$. Interactions between these components and cancer cells contribute to angiogenesis, intravasation, and metastasis in lung cancer. The key molecules by which cancer cells cooperate with the microenvironment are candidate biomarkers or drug targets [6].

Among these functional mechanisms, exosomes carrying large amounts of information and molecules play an important role in intercellular communication and are indispensable mediators of various processes in the TME [7]. Exosomes were named in 1987 and were first described by Johnstone et al. in 1983 as small vesicles

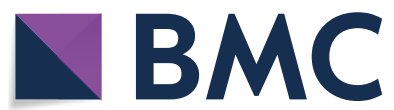

(c) The Author(s) 2021. This article is licensed under a Creative Commons Attribution 4.0 International License, which permits use, sharing, adaptation, distribution and reproduction in any medium or format, as long as you give appropriate credit to the original author(s) and the source, provide a link to the Creative Commons licence, and indicate if changes were made. The images or other third party material in this article are included in the article's Creative Commons licence, unless indicated otherwise in a credit line to the material. If material is not included in the article's Creative Commons licence and your intended use is not permitted by statutory regulation or exceeds the permitted use, you will need to obtain permission directly from the copyright holder. To view a copy of this licence, visit http://creativecommons.org/licenses/by/4.0/. The Creative Commons Public Domain Dedication waiver (http://creativecommons.org/publicdomain/zero/1.0/) applies to the data made available in this article, unless otherwise stated in a credit line to the data. 
released from maturing sheep reticulocytes containing externalised protein components of reticulocytes. They were later recognised as important regulators of cell function and intercellular communication.

Exosomes transport proteins (cytosolic and transmembrane proteins), lipids, and nucleic acids (microRNAs [miRNAs], mRNAs, long non-coding mRNAs, and DNA) to target cells, thus regulating their behaviour [8-10]. Exosomes, with a diameter of $30-100 \mathrm{~nm}$, are intraluminal vesicles formed by the inward budding of the endosomal membrane and are secreted after fusion on the cell surface [11]. In this review, we have described the effects of exosomes on various cell types in the lung cancer microenvironment, with an emphasis on the implications for diagnosis and treatment.

\section{Origin and characteristics of exosomes}

Exosomes form by inward budding in the plasma membrane, and are classified as early and late endosomes, known as multivesicular bodies. Numerous intraluminal vesicles form by the invagination of multivesicular body membranes. Exosome release is regulated by a number of genes and proteins. For example, miR134 and miR-135b precisely regulate YKT6 expression in lung cancer cells, which in turn controls exosome release [12]. Furthermore, exosomes are produced by a variety of cells in the lung TME, including lung cancer cells, cancer-associated fibroblasts (CAFs), tumour-associated macrophages (TAMs), and dendritic cells (DCs). CAFs play a critical role in the epithelial-mesenchymal transition (EMT), which is associated with malignant progression, via exosomes, and exosomal SNAI1 is crucial for this process. Exosomes derived from macrophages also regulate lung cancer cell proliferation in the TME [13]. Duan et al. found that let-7a-5p could be transported from macrophages to lung cancer cells as a macrophage exosome cargo and could directly target BCL2L1, thereby promoting A549 cell autophagy and cell death via the PI3Ky pathway. Expression levels of the lung cancer marker proteins MYC, EGFR, and vimentin are also altered by the aberrant expression of BCL2L1 [14]. The miRNAs miR-193a, miR-210, and miR-5100 are transferred by exosomes derived from bone marrow-derived mesenchymal stem cells (BMSCs) to neighbouring cancer cells, thereby activating STAT3 signalling and promoting cancer cell invasion and EMT [15]. Xu et al. found that microvascular endothelial cell exosomes promoted tumour cell survival via the upregulation of S100A16 in the microenvironment of SCLC with brain metastases, which are associated with a poor prognosis [16]. DCs play a critical role in adaptive immunity in lung cancer. They are indispensable for the response to checkpoint inhibitor immunotherapy [17]. There are at least two phenotypes of DC-derived exosomes: bone marrow mature DC-derived exosomes and bone marrow immature DC-derived exosomes. Researchers have identified 139 miRNAs in mature DC-derived exosomes with key roles in cell biology and function [18, 19]. T lymphocyte- and B lymphocyte-derived exosomes also play important roles in the immune microenvironment. Recently, B lymphocytes have been shown to facilitate the impaired function of CTL by enzymatic activities in B lymphocyte-derived exosomes [20]. Additionally, chimeric antigen receptor (CAR)-T cells release exosomes that carry CAR on their surface and inhibit tumour growth [21]. Exosomes can be produced by a variety of immune cells in the TME; however, the mechanism of action of these exosomes in lung cancer requires further study.

\section{Exosome targeting and uptake}

Exosomes can be ingested by a variety of cells in the TME and exert functions via proteins, nucleic acids, and other substances. First, the recognition of exosomes requires membrane protein interactions. CD169 recognises exosomes and mediates the immune response to exosome antigens. The adhesion of $\mathrm{B}$ cellderived and DC-derived exosomes is CD169-dependent [22]. After recognising exosomes, some proteasome components, such as Tim family members Tim 1 and Tim4, bind by exosomal phosphatidylserine [23]. Additionally, exosomes express chemokines, including CCLs and CXCLs, to attract leukocytes, providing an alternative explanation for exosome cellular recognition [24]. After recognition, exosomes are internalized into recipient cells. Tetraspanins on exosomes are part of the antigen recognition system and contribute to the activation of signalling pathways induced by exosomes. The merging of the exosome cytosol and cytoplasm is achieved by membrane fusion at the plasma membrane or by uptake followed by fusion with the endosomal membrane [18]. Exosomes are taken up by many endocytic pathways, including clathrin-mediated endocytosis, caveolin-dependent endocytosis, macropinocytosis, phagocytosis, and lipid rafts [25, 26]. Caveolin-1 and clathrin heavy chain mediate caveolae-dependent endocytosis and clathrin-dependent endocytosis, respectively. The absorption of exosomes is reportedly dependent on the recipient cell and not on exosomal surface molecules, and this process can be visually observed by immunofluorescence microscopy[27, 28]. Extensive studies of exosome targeting and uptake have provided a basis for the development of new clinical treatment methods and dosage forms. 


\section{Functions of exosomes in the lung cancer microenvironment}

Tumour-associated macrophages regulation by lung cancer-associated exosomes

Tumour-associated macrophages (TAMs) have been linked to lung cancer cell initiation, progression, and metastasis in the TME [29]. The key mechanisms underlying such functions are classical activation and alternative activation of macrophages. The classical activation (M1) of macrophages is characterised by the production of antineoplastic and proinflammatory macrophages, whereas alternative activation (M2) is related to immunosuppression, tumourigenesis, and angiogenesis [30]. Exosomes promote macrophage polarisation, resulting in immunosuppression, angiogenesis, and tumour progression. NSCLC exosomes can induce M0 macrophages and myeloid-derived suppressor cells to differentiate into M2 macrophages. Additionally, one study also confirmed that exosome induced M2 polarization might not be p53 gene dependent [31]. In a recent study, hypoxia stimulated tumour-derived exosome secretion promoted oxidative phosphorylation in TAMs by transferring let7a miRNA and by suppressing the insulin-Akt-mTOR pathway. Hypoxia-induced exosomes enhance macrophage recruitment and promote M2-like polarisation in vitro and in vivo [32]. Another study showed that exosomes from hypoxic lung cancer cells polarized macrophages to M2-type via miR-103a. Exosomal miR-103a decreased PTEN levels or increased Akt/Stat3 activation and several immunosuppressive factors [33]. By studying SK-LU-1 lung adenocarcinoma cell derived exosomes and J774 macrophages, Trivedi's team found that the expression of exosomal miR-125b et al. from SK-LU-1 cell were increased by double-targeted (wild-type p53 and microRNA-125b) transfection of hyaluronic acidbased nanoparticles. At the same time, J774 macrophages treated with these exosomes repolarized towards M1 phenotype (pro-inflammatory and antitumour type) [34]. Tumour-derived exosomes influence the phenotype and function of macrophages. Many studies have focused on the effect of tumour-derived exosomes on TAMs, while the interaction between macrophages and other immune cells via exosomes remains to be further studied.

\section{Dendritic cells regulation by exosomes in the TME of lung cancer}

Dendritic cells (DCs) play an essential role in the regulation of tumour-specific immune responses. DC-based immunotherapy is unsatisfactory due to the poor immunogenicity of cancer cells and low uptake efficiency of antigens, even though DCs are the most potent antigen-presenting cells [35]. Lung tumour cell-associated exosomes can more effectively deliver a variety of tumour antigens to DCs [36]. Wang et al. have reported that tumour-associated exosomes stimulate DC maturation and enhance $\mathrm{MHC}$ cross-presentation, which directly promotes a tumour-specific cytotoxic $\mathrm{T}$ lymphocyte response. Exosomes also reduce $\mathrm{PD}-\mathrm{L} 1$ expression on DCs, resulting in a decrease in the Treg population [37]. Additionally, in vitro analyses have shown that DC-derived exosomes can transfer MHC class I and II complexes to DCs and trigger CD8+and CD4+ T lymphocyte activation [38, 39]. It has been shown that exosomes activate DC maturation, while DCs incubated with exosomes derived from Rab27a-overexpressing cells promote $\mathrm{CD} 4+\mathrm{T}$ cell proliferation [40].

\section{Interaction between NK cells and exosomes in the TME}

Natural killer (NK) cells are independent, non-specific immune cells. They can directly kill tumour cells without MHC restriction to the target [41]. However, tumour cells impact normal functions of NK cells and impair cytotoxicity in the TME. The degree of NK cell infiltration is positively related to the survival rate in lung cancer [42]. Decreased expression of the NK cell-activated receptor NKG2D in the TME indicates immune tolerance [43]. Hypoxia inhibits the immune function of NK cells. Exosomes derived from hypoxic tumour cells transfer TGF- $\beta 1$ to NK cells and inhibit NK cell function by suppressing NKG2D. Additionally, miR-23a in hypoxic exosomes acts as an immunosuppressive factor by inhibiting CD107a expression in NK cells [44]. NKG2D endocytosis decreases the expression of surface receptors and regulates signalling in NK cells [45]. Exosome-associated NKG2D ligand could combine with NKG2D, triggering signalling in NK cells [46]. DNAX accessory molecule-1 (DNAM1), which functions like NKG2D, is another key receptor of NK cells. DNAM1 is expressed more in infiltrating NK cells of primary lung tumours compared to the expression in surrounding normal tissues. NK cells have a cytolytic effect in lung tumours via exosomal DNAM1 receptor-ligand binding and endocytosis [47].

\section{Treg/T cell regulation by exosomes in the TME}

The proportion of $\mathrm{CD} 4^{+} \mathrm{CD} 25^{+} \mathrm{Foxp} 3^{+} \mathrm{T}$ regulatory cells (Tregs) and functional alterations of $\mathrm{T}$ lymphocyte subsets in the TME are critical for the immune escape of lung cancer cells [48]. Lung cancer cellderived exosomes act on DCs, thereby increasing Treg differentiation in the TME, decreasing the proportion of $\mathrm{CD} 4+\mathrm{T}$ cells, and decreasing IFN- $\gamma$ production. However, PD-L1 blockage partially modulates the exosome-induced DC-associated immunosuppressed microenvironment [49]. PD-L1-mediated immunotherapy is widely used in clinical settings. Exosomal PD-L1 
is a new target for the regulation of $\mathrm{T}$ cell immune function and the tumour immune microenvironment. Tumour cell-derived exosomal PD-L1 suppresses $\mathrm{T}$ cell activation and contributes to immunosuppression. However, blocking of exosomal PD-L1 and anti-PDL1 antibodies can inhibit tumour growth $[50,51]$. In addition, Microsatellite instability (MSI)is also closely associated with PD-1/PD-L1 expression and MSI tumours have high immunogenicity [52]. The transfer of exosomes containing Let-7d from Tregs to helper $\mathrm{T}$ lymphocyte 1 (Th1) cells contributes to the prevention of diseases, thereby providing a mechanism underlying Treg-mediated immunosuppression by miRNA-containing exosomes [53]. Epidermal growth factor receptor (EGFR) is closely related to lung cancer. Huang et al. found that exosomes containing EGFR could induce tolerogenic DCs and generate tumour antigen-specific Tregs [54]. The oncogenic Ras protein Kirsten rat sarcoma viral oncogene homolog (KRAS) is frequently mutated in lung cancer. $\mathrm{CD}^{+}$naïve $\mathrm{T}$ lymphocytes incubated with tumour-derived exosomes from mutant $\mathrm{KRAS}^{+/+}$NSCLC cells induce Foxp ${ }^{+}$Treg generation by phenotypic switching. Foxp3 regulates Treg functions [55]. This conversion is related to IFN signalling, which eventually results in immunosuppression [56].

\section{Myeloid-derived suppressor cells interact with exosomes in the TME}

Myeloid-derived suppressor cells (MDSCs) are divided into the following two groups: M-MDSCs, which are morphologically similar to monocytes, and PMNMDSCs, which resemble polymorphonuclear cells [57]. MDSCs require the activation of inflammatory cytokines, such as IL- 6 and TNF- $\alpha$, and tumour-associated cytokines, such as GM-CSF and M-CSF, to form a population of immunosuppressive cells [58]. MDSCs regulate $\mathrm{T}$ cell function to form an immunosuppressive microenvironment, and exosomes with cytokines play a role in this process. Tumour exosomal PGE2 and TGF- $\beta$ strengthen the induction of MDSCs, activate the upregulation of Cox2, IL-6, VEGF, and ARG-1 in MDSCs, and promote $\mathrm{T}$-exosome-mediated tumour proliferation [59]. MDSCs are the main target cell population of exosomes from lung cancer cells. MDSCs internalise lung cancer-derived exosomes together with soluble factors (miR-126-3p, miR-27b, miR-320, and miR-342-3p) and upregulate the expression of suppressive molecules, including ARG-1 and TGF- $\beta$ [60]. Little is known about the role of exosomes in MDSCs, and there is no direct evidence that exosomes from lung cancer cells can directly regulate the phenotypes and functions of MDSCs.

\section{Regulation of epithelial-mesenchymal transition by lung cancer-derived exosomes}

Epithelial-mesenchymal transition (EMT) is a key mechanism for initiating lung cancer cell invasiveness and metastasis [61]. Exosomes relay signals from CAFs to lung cancer cells and play an important role in EMT [62]. A recent study has revealed that CAFs deliver SNAI1 exosomes to lung cancer cells to induce EMT. Markers of EMT, including E-cadherin, vimentin, and $\alpha$-smooth muscle actin $(\alpha-S M A)$, are upregulated during exosome-induced EMT [13]. ZEB1 mRNA is a major EMT transcription factor in mesenchymal cells in NSCLC. Oncogenic exosomes derived from mesenchymal NSCLC cells can transfer chemoresistance and mesenchymal phenotypes to recipient cells by ZEB1 mRNA in exosomes [63]. These results provide the mechanism by which parental epithelial cells transform into mesenchymal lung cancer cells with the chemoresistance phenotype. miRNAs in exosomes also affect lung cancer carcinogenesis and metastasis. One of these miRNAs, miR-499a-5p, is upregulated in lung cancer cell lines and their exosomes. Tumour-derived exosomal miR-499a-5p has diagnostic and therapeutic value and promotes EMT via the mTOR signalling pathway in lung cancer [64]. Exosomal miR-9 from lung cancer cells effectively acts on HUVECs by downregulating the SOCS5-JAK-STAT pathway, which promotes endothelial cell migration and angiogenesis [65]. Increasing research has demonstrated the important role of bone marrow-derived mesenchymal stem cells (BMSCs) in EMT. Exosomes derived from BMSCs, which are components of the lung cancer microenvironment, mediate the transfer of miR-193a-3p, miR-210-3p, and miR-5100 and promote cancer cell invasion and EMT by activating STAT3 signalling [15]. These results suggest that transcription factors, mRNAs, and microRNAs in exosomes all play important role as mediators of EMT, thereby promoting lung cancer cell invasion, infiltration, and metastasis.

\section{Cancer-associated fibroblasts regulation by lung cancer-derived exosomes}

Cancer-associated fibroblasts (CAFs) are a major cellular component of TME in most solid cancers. Lung cancer cells can transform the phenotype of fibroblasts via exosomes and related factors. Exosome-associated miR-142-3p promotes the transformation of lung fibroblast cells to CAFs via TGF- $\beta$ signalling [66]. Interacted, CAFs also promote tumour cells proliferation. It is generally believed that CAFs promote tumour angiogenesis. Some studies have shown that exosomes from patients with lung cancer can induce cancer cell reprogramming [67]. Exosomes that overexpress miR-210 can activate the functions of CAFs and increase the expression of 
proangiogenic factors, such as MMPs, FGF2, and VEGFA [68]. CAFs deliver the transcription factor SNAI1 to lung cancer cells via exosomes, thereby inducing epithelial transformation via $C D H 1$ encoding E-cadherin and VIM encoding Vimentin [13]. In terms of energy metabolism, exosomes supply nutrients to starving cancer cells by a mechanism similar to micropinocytosis. CAF-derived exosomes with amino acids, lipids, and TCA-cycle intermediates $[69,70]$ are ingested by cancer cells for central carbon metabolism and promote tumour growth under nutrient deprivation or nutrient stress conditions [71]. In addition to controlling somatic cell senescence, telomerase can also inhibit lung cancer cells. Telomerase is activated in more than $90 \%$ of the cancer cells $[72,73]$. Similarly, $h T E R T$ mRNA has been detected in exosomes isolated from sera of patients with lung cancer. The transfer of exosomal telomerase from cancer cells into fibroblasts may contribute to alterations in the TME [74].

\section{Angiogenesis regulation by exosomes in the TME}

Various studies have evaluated the role of hypoxia during interactions between immune cells and EMT components. Lung cancer-derived exosomes increase under hypoxic conditions and play a critical role in angiogenesis. miRNAs in lung cancer cell-derived exosomes have important functions under hypoxic conditions [75]. Exosomal miR-23a targets prolyl hydroxylase 1 and 2 (PHD1 and 2) and suppresses expression in endothelial cells. Hypoxia-inducible factor- $1 \alpha$ (HIF-1 $\alpha)$ accumulates in endothelial cells, thereby increasing angiogenesis. Additionally, exosomal miR-23a inhibits the tight junction protein ZO-1, which is related to vascular permeability and cancer cell migration [76]. Radiotherapy, one of the most important treatment approaches in lung cancer, also affects exosome production. In an in vitro experiment, exosomes released from $\gamma$-irradiated cells or hypoxic cells activated lung tumour progression. Furthermore, angiopoietin-like 4 (ANGPTL4) derived from exosomes contributes to angiogenesis, suggesting that it is a potential diagnostic biomarker of lung cancer [77]. The process of tumour angiogenesis is also closely related to fibroblasts and their proangiogenic factors. According to Fan et al., miR-210 is encapsulated in exosomes, secreted by lung cancer cells, and eventually acts on fibroblasts. The teneleven translocation 2 (TET2) and JAK2/STAT3 signalling pathway of CAFs is a target of miR-210 in the process of angiogenesis, which promotes the release of the proangiogenic factors vascular endothelial growth factor (VEGF), MMP9, and FGF2 [68]. The overexpression of tissue inhibitor of metalloproteinase-1 (TIMP-1) also leads to the accumulation of miR-210 in exosomes and thus promotes angiogenesis [78]. The
STAT3 signalling pathway is not only a target for exosomal miRNAs in the promotion of angiogenesis but also boosts the release of miRNAs. STAT3 upregulates exosomal miR-21 levels in transformed HBE cells. Interestingly, miR-21 in exosomes further activates the STAT3 signalling pathway in HBE cells, which increases VEGF levels and induces tumour angiogenesis [79]. Based on the important effect of exosomal miRNAs on angiogenesis, they have been evaluated as treatment targets in NSCLC. For example, exosomal miR-497 effectively inhibits the expression of VEGF-A and suppresses tumour growth. Therefore, it may be a tool for the development of lung cancer therapies [80].

\section{Microenvironmental regulation by exosomes}

The premetastatic TME (pre-metastatic niche) in lung cancer is an important cause of induction of metastasis. Primary lung cancer-derived exosomal RNAs promote neutrophil recruitment by activating TLR3 in lung epithelial cells via the NF-kB and MAPK pathways [81]. TGF- $\beta$ has long been a pivotal adaptor in the lung cancer TME. It contributes to the development of cancer and directly impairs $T$ cell immune function $[82,83]$. Recent studies have found that TGF- $\beta$ also has a regulatory effect on exosomal factors. TGF- $\beta$-pretreated A549 cell-derived exosomes increase the expression of MMP2 at the gene and protein levels and regulates vascular permeability [84]. Thyroid transcription factor-1 (TTF-1) is mainly expressed in lung adenocarcinomas and regulates angiogenesis activity in the TME. Both vascular endothelial growth factor (VEGF) and granulocyte-macrophage colony-stimulating factor (GM-CSF) are regulated by TTF-1, which reprograms lung adenocarcinomas that secrete TME factors in angiogenesis [85]. Leucine-rich-alpha2-glycoprotein 1 (LRG1) is upregulated in NSCLC tissues and promotes NSCLC cell invasion. NSCLC cell-derived exosomes with LRG1 activate the TGF- $\beta$ signalling pathway and thus promote angiogenesis [86]. CAF-derived exosomes also play a role in the microenvironment of lung cancer by promoting EMT. MiR-210 secreted by CAF-exosomes could target UPF1, promote the PTEN/PI3K/AKT signalling pathway, and contribute to NSCLC invasion by regulating EMT factors, such as E-cadherin, N-cadherin, and vimentin [87]. These studies suggest that exosomal RNAs and proteins are novel therapeutic targets and predictive markers of tumour metastasis in lung cancer.

Table 1 shows the interaction of exosomes between different cells in TME of lung cancer and the effect of exsome from lung cancer cell on TME was illustrated on Fig. 1. 


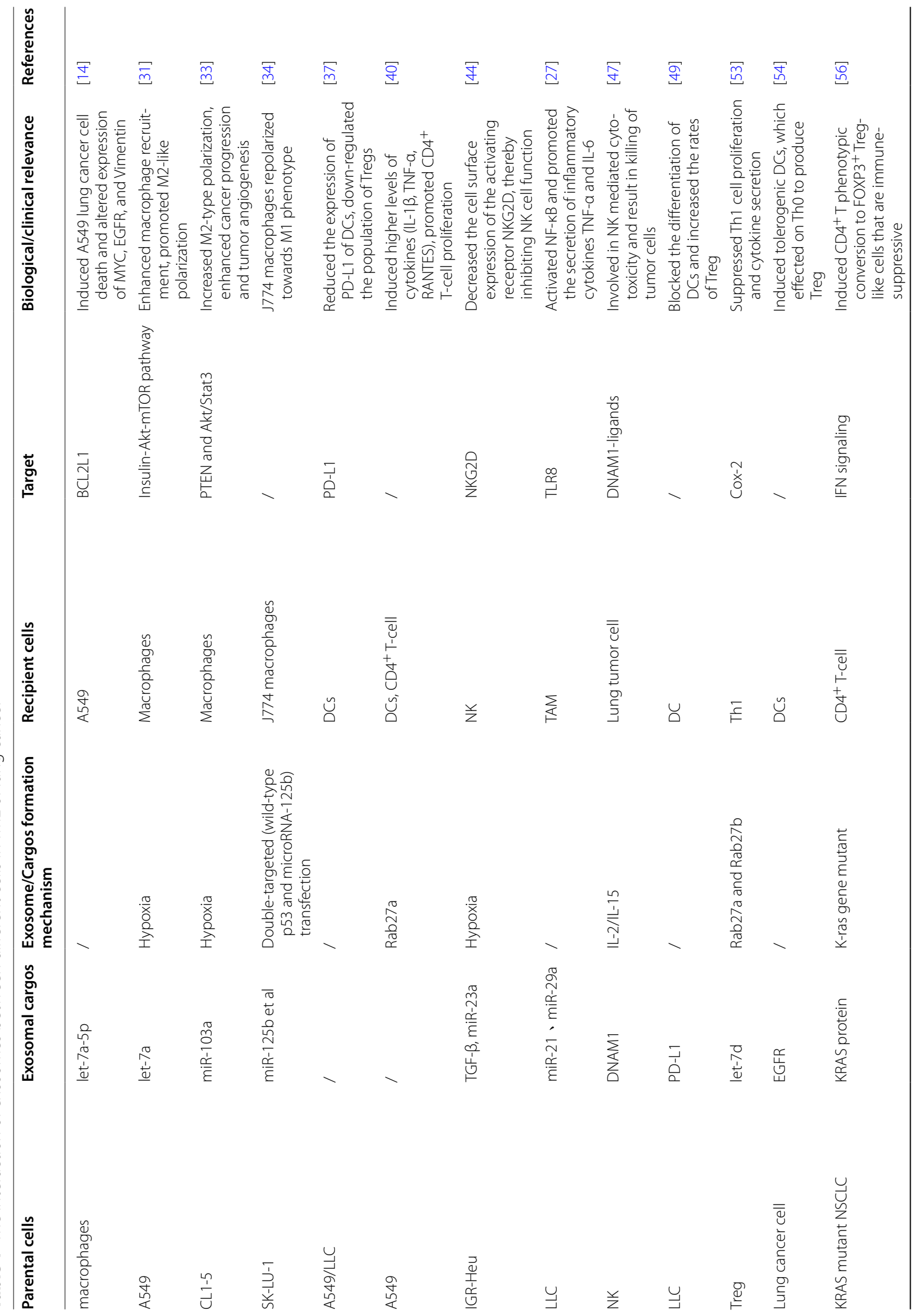




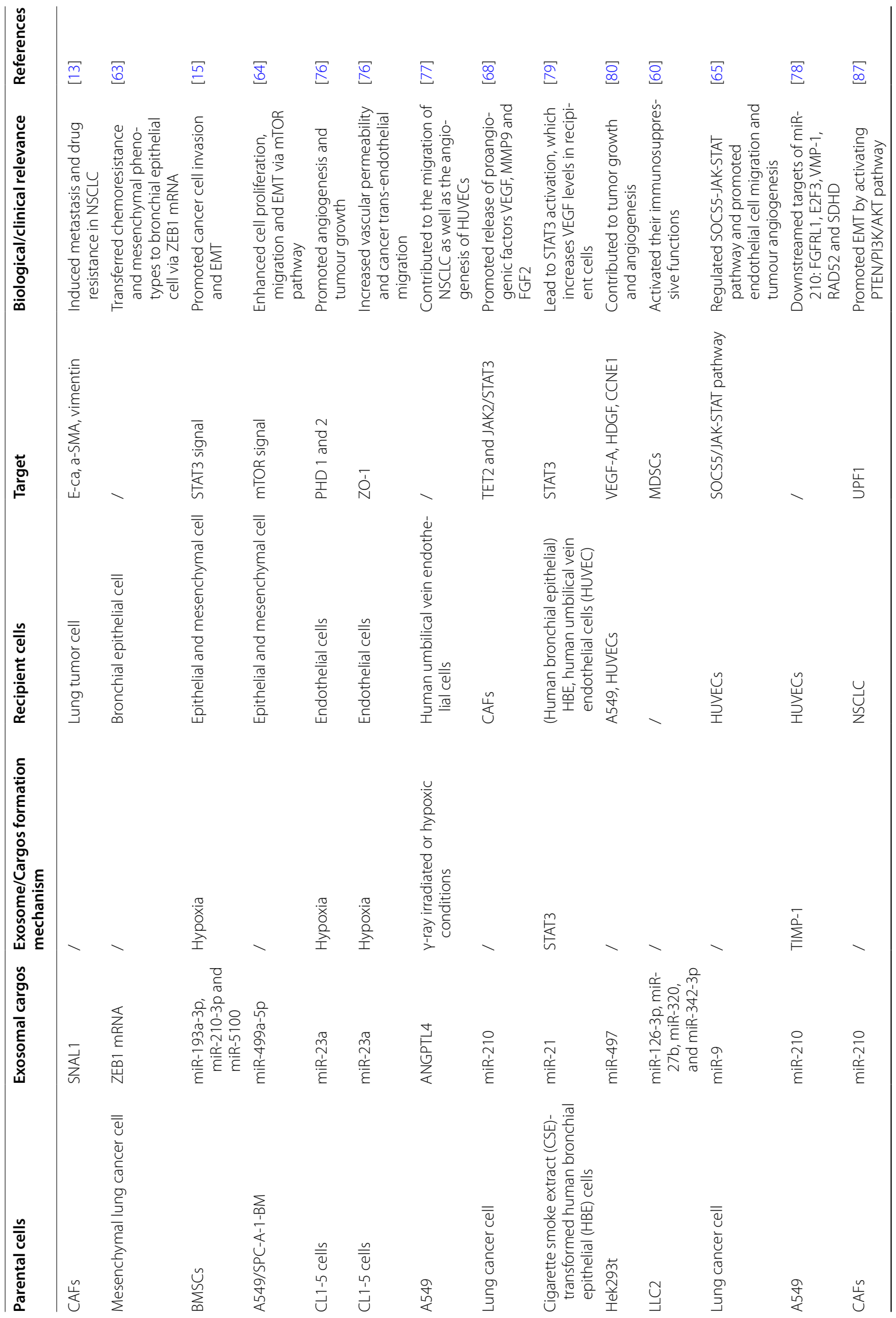




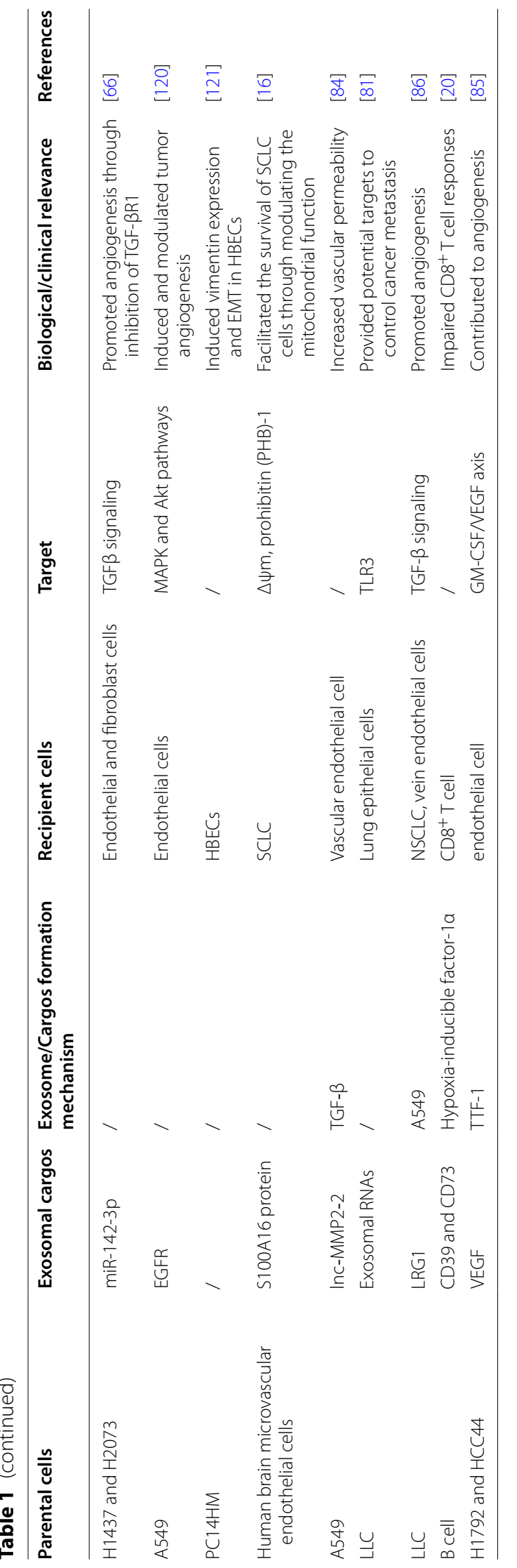




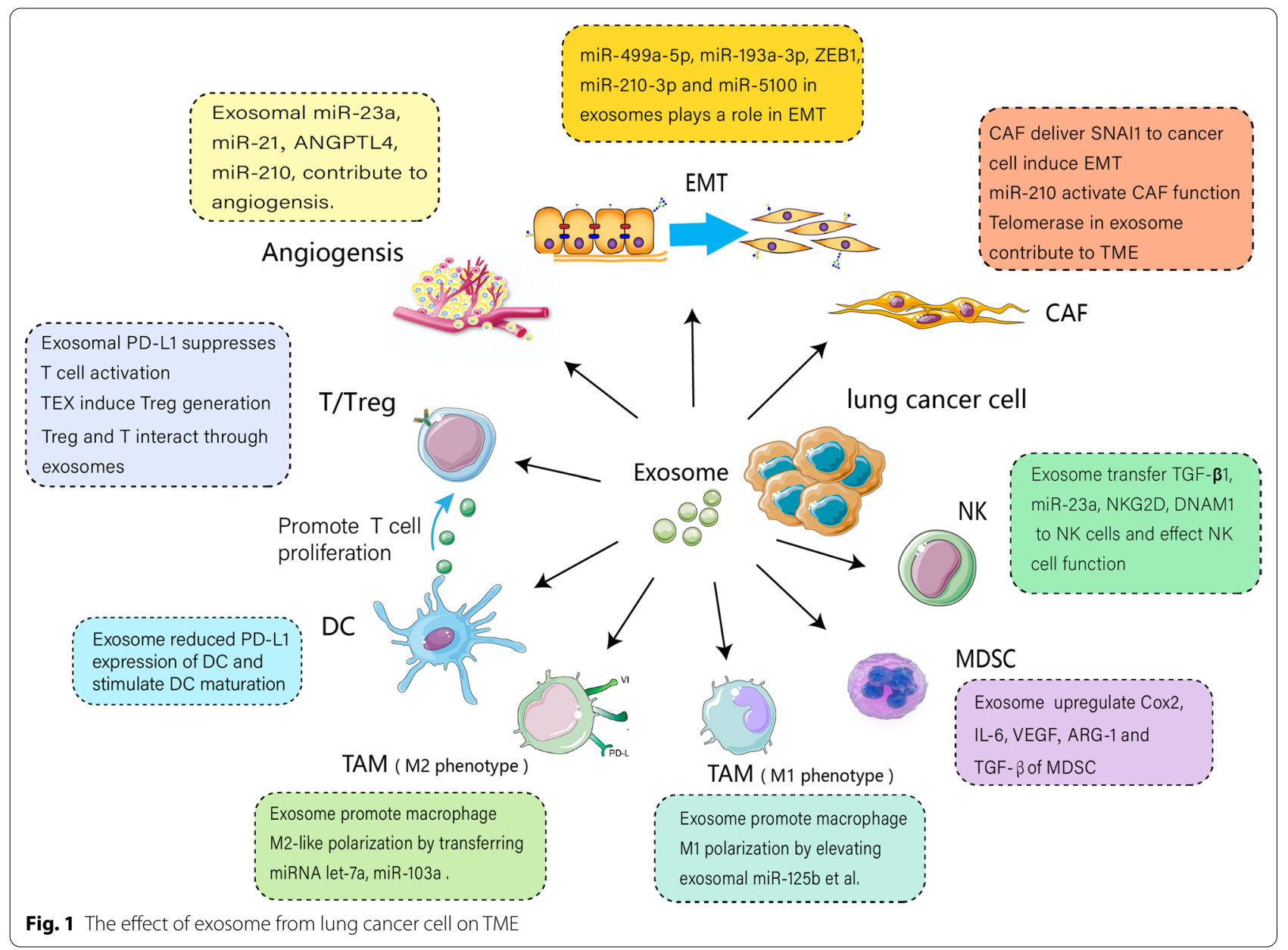

\section{Roles of exosomes in treatment resistance}

The progression of multidrug resistance is the major obstacle to maintain effectiveness of chemotherapy in lung cancer [88]. The TME is enriched with DDP-resistant lung cancer cell-derived exosomes. These exosomes with miR-100-5p could be absorbed by other lung cancer cells and exerted their DDP resistance function. Qin and colleagues explained that cancer cells could be regulated by miRNAs themselves and the TME in vitro [89]. These results have been verified in vivo using a gemcitabine-resistant (GR) cell line. GR cell-derived exosomes transfer miR-222-3p, thereby contributing to malignancy in NSCLC by targeting SOCS3 after endocytosis. Additionally, the miR-222-3p level in serum exosomes may predict gemcitabine sensitivity and worse prognosis in NSCLC [90]. Radiotherapy is another promising method to completely cure localized non-metastatic cancer, in addition to surgical resection. The level of serum exosomal miR-208a could be elevated by X-ray irradiation in patients with NSCLC. miR-208a could target p21 and activate the $\mathrm{AKT} / \mathrm{mTOR}$ pathway, thereby promoting cell proliferation and inducing radio-resistance. Therefore, exosomal miR-208a could serve as a target to enhance the efficacy of radiotherapy [91]. Some miRNAs have a radiosensitising effect. For example, miR200c and miR148b both inhibit proliferation by regulating EMT and possess radiosensitising effects [92, 93]. Wu et al. found that exosomal miR-96 isolated from H1299 enhanced cell malignancy and cisplatin resistance by targeting LIM-domain only protein 7 (LMO7) [94]. The role of exosomes in resistance to targeted therapy has also been investigated. Exosomal PLAUR regulates the EGFR/ $\mathrm{AKT} /$ survivin signalling pathway and induces gefitinib resistance [95]. Similarly, exosome-derived miR-564 and miR-658 also induce gefitinib resistance, and targeting these miRNAs may reverse resistance [96]. Additionally, UCA1 in exosomes may be another therapeutic target for patients with EGFR-positive lung cancer. Resistance to tyrosine kinase inhibitors has become a main factor limiting clinical efficacy for patients with advancedstage NSCLC. Zhang et al. confirmed that serum lncRNA RP11-838N2.4 expression was improved in patients with 
resistance to erlotinib. Furthermore, the knockdown of the lncRNA RP11-838N2.4 could promote erlotinib cytotoxicity [97]. Another target for the reversal of erlotinib resistance is the lncRNA H19. H19 from exosomes can regulate ATG7 expression by binding to miR-615-3p, thereby promoting erlotinib treatment resistance. Therefore, H19 may be another target for patients with erlotinib resistance [98].

\section{Exosomes as diagnostic and therapeutic targets}

Exosomes in the TME may be novel diagnostic and therapeutic targets for NSCLC. YKT6 in lung cancer cells regulates exosome release. A clinical study has shown that in NSCLC, YKT6 in tumour samples is associated with a shorter disease-free survival and overall survival [12].

Various lncRNAs have been identified as promising therapeutic targets. MiR-96 is a candidate serum biomarker and therapeutic target for NSCLC. Melanoma differentiation-associated gene-9 (MDA-9)/Syntenin is another therapeutic target for lung adenocarcinoma; this locus promotes cancer invasion and metastasis as a key regulator of Slug and Slug-mediated EMT [99]. NSCLC cell-released exosomal miR-619-5p could promote angiogenesis by targeting RCAN1.4 and induced the growth and metastasis of lung cancer cells. A clinical study found that miR-619-5p was expressed at higher level in exosomes isolated from the plasma of patients with NSCLC compared with the level in healthy individuals[100]. Exosome-derived EGFR has also recently been identified as a diagnostic marker for NSCLC based on its high expression in plasma exosomes of patients with NSCLC, and it can be specifically captured by CD81 antibodies [101]. In terms of angiogenesis, radiation-induced ANGPTL4 derived from exosomes contributes to angiogenesis and lung cancer cell migration, suggesting that exosomal ANGPTL4 is a therapeutic target [77].

\section{Exosomes of the TME as prognostic biomarkers for lung cancer}

Exosomes are promising tools for tumour diagnosis and treatment $[4,8]$. MicroRNAs in exosomes may be diagnostic biomarkers for lung cancer. Zhang et al. found that the downregulation of exosomal let-7a-5p with the upregulation of the target gene $B C L 2 L 1$ could be a useful biomarker for poor survival in patients with lung adenocarcinoma [102]. A large number of studies have shown that miR-21 is associated with survival and is actively involved in the modulation of malignant transformation and progression in NSCLC [103]. Exosomal miR106b may elevate the expression of MMP-2 and MMP-9, which play a role in angiogenesis in the TME, and may enhance the invasive ability of NSCLC. Additionally, serum exosomal miR-106b in patients with lung cancer is associated with the TNM stage and lymph node metastasis [104]. Another TME factor with prognostic value is NEK2, a target of miR-486-5p, which is associated with the TNM stage. Exosomal miR-486-5p is downregulated in the serum of patients with lung cancer and contributes to tumour formation via effects on the EMT [105]. High levels of MDA-9/Syntenin and Slug are related to poor overall survival in patients with lung adenocarcinomas [99]. Exosomes are also a new tool for gene sequencing of targeted therapies. Clinical studies have shown that RNA/DNA detection in exosomes can improve the detection rate of patients who are positive for EGFR mutations (including the L858R and T790M mutations) $[106,107]$.

Table 2 expresses a summary of exosomes related experiments and studies contributing to radiotherapy, chemotherapy, targeted therapy, diagnosis and prognosis.

\section{Exosomes as biomarkers for liquid biopsy of lung cancer}

Liquid biopsy is a diagnostic procedure that describes information about cancer-derived substances obtained from blood sample. The sample information of the liquid biopsy mainly comes from: circulating tumour cells (CTCs) of blood sample, circulating cell-free DNA (cfDNA) released into the blood from tumour cells and normal cells and cell-free RNA (cfRNA) enriched in exosomes from tumour cells [108]. It makes up for the inadequacy of tissue biopsy in advanced NSCLC patients with poor state, lung cancer very early detection, the side effects of interventional biopsy procedures, insufficient tissue quantity, and false positive molecular detection analysis [109]. Liquid biopsy is expected to be another important means for lung cancer diagnosis and gene sequencing analysis. Clinical diagnosis of patients with lung cancer pneumomeningeal metastasis (LM) is difficult. Serum exosomal miR-483-5p and miR-342-5p may play a role in the diagnosis of these patients and may replace cerebrospinal fluid in predicting LM of NSCLC [110]. Similarly, exosomal miR-17-5p expression is significantly up-regulated in NSCLC patients. Based on this, the combination of exosomal miR-17-5p, carcinoembryonic antigen (CEA), cytokeratin 19 fragment (CYFRA211 ) and squamous cell carcinoma antigen (SCCA) is considered to be a newly developed diagnostic panel of NSCLC [111]. Extracellular Vesicle (EVs)-Derived CD5L protein expression was detected to be associated with cancer tissue in clinic. This result suggests that CD5L may be another potential biomarker for noninvasive diagnosis of NSCLC. The EVs were detected to be about 76-194 $\mathrm{nm}$ in diameter, which included the category of exosomes [112]. In addition, the combination of miR21-5p, miR-223-3p, miR-155-5p and miR-126-3p may be 


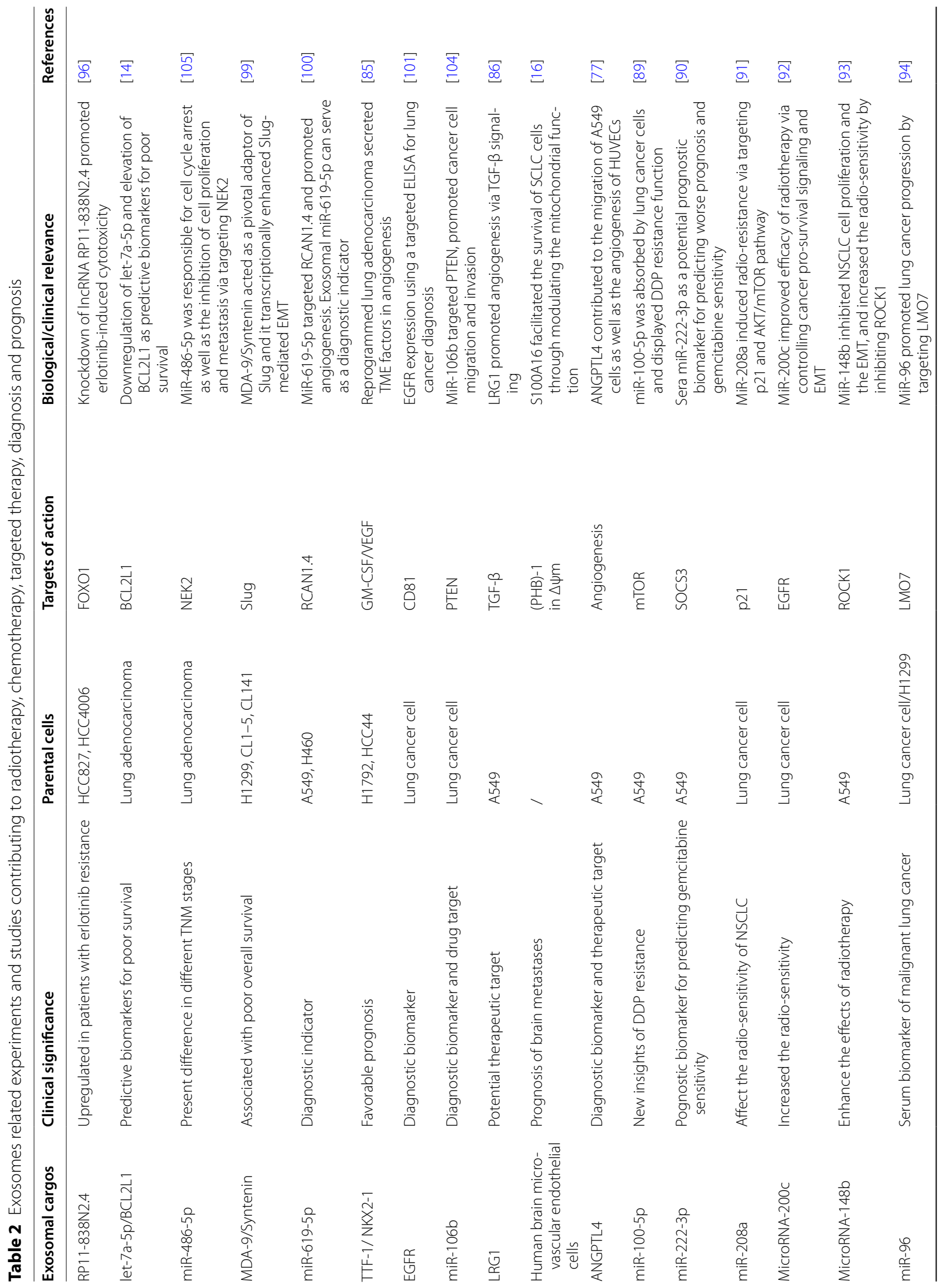




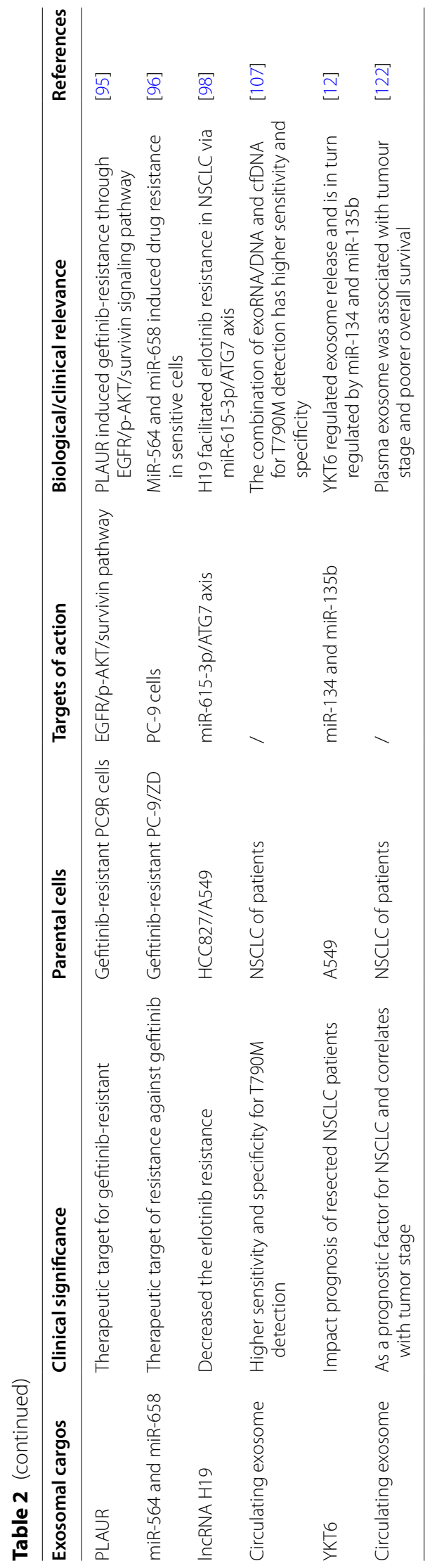


a potential diagnostic biomarker for lung cancer [113]. In terms of EGFR mutation detection, combining exosomal RNA and cfDNA (exoNA) can improve the sensitivity of EGFR mutation detection in liquid biopsy from NSCLC patients. The sensitivity of EGFR mutation positive detection by exoNA method can reach 98\% [114]. Exosomal nucleic acids are more sensitive to the identification of associated mutations than cfDNA. This is of great significance for the selection of targeted therapy [115].

PD-L1 in serum exosomes can be used as a quantitative factor for tumour PD-L1 status, which may be helpful in predicting the clinical outcome of anti-PD-1 therapy in NSCLC patients [116]. With the development of immunotherapy, microsatellite instability (MSI) and mismatch repair deficiency (MMRD) tumours have high immunogenicity and have been used as predictive biomarkers for PD-1 inhibitor efficacy and demonstrated in clinical trials of anti-PD-1 therapy [117]. MSI can also be diagnosed by analysis of miRNA-mRNA network in exosomes biomarker sources and therapeutic applications [118]. Detection of MSI and MMRD gene sequences in exosomes by liquid biopsy is of great significance for PD-1 and PD-L1 immunotherapy [119].

\section{Conclusion}

Functional studies of non-coding RNAs and proteins in exosomes provide new insights into reshaping the TME. In terms of clinical application, a large number of noncoding RNAs and proteins have been found in exosomes, which are expected to become an indispensable tool for the diagnosis and prediction of lung cancer in clinic. However, there remains a lack of clinical studies with large samples to provide evidence support. It is particularly important to identify the precise components that act key roles in tumour processes. Ongoing experimental and clinical studies of exosomes may provide new ideas for improvement of TME and treatment of lung cancer.

\begin{abstract}
Abbreviations
CAF: Cancer-associated fibroblast; DC: Dendritic cell; ECM: Extracellular matrix; EMT: Epithelial-mesenchymal transition; NK cell: Natural killer cell; NSCLC: Non-small cell lung cancer; SCLC: Small cell lung cancer; TAM: Tumour-associated macrophage; TME: Tumour microenvironment; Treg: Regulatory T cells.
\end{abstract}

Acknowledgements

Not applicable.

\section{Authors' contributions}

$\mathrm{RQ}$ contributed to study concepts, design, table and drafting of the manuscript. YZ, QG, XM, MC and WH contributed to manuscript editing. $\mathrm{HZ}$ and $\mathrm{BH}$ contributed to manuscript review. All authors read and approved the final manuscript.

\section{Funding}

This project is supported by a grant of the Young Elite Scientists Sponsorship Program by CAST (YESS), No. QNRC1-03; The National Natural Science Foundation of China (NSFC), No. 8177151981.
Availability of data and materials

The primary data for this study is available from the authors on direct request.

\section{Declarations}

Ethics approval and consent to participate

Not applicable.

\section{Competing interests}

The authors declare that they have no competing interests.

\section{Author details}

${ }^{1}$ Department of Oncology, Guang'anmen Hospital, China Academy of Chinese Medicine Sciences, Xicheng District, Beijing, China. ${ }^{2}$ Beijing University of Chinese Medicine, Chaoyang District, Beijing, China. ${ }^{3}$ Shaanxi University of Chinese Medicine, Qindu District, Xianyang, Shaanxi, China.

Received: 2 October 2020 Accepted: 22 May 2021

Published online: 30 June 2021

References

1. Bray F, Ferlay J, Soerjomataram I, Siegel RL, Torre LA, Jemal A. Global cancer statistics 2018: GLOBOCAN estimates of incidence and mortality worldwide for 36 cancers in 185 countries. CA Cancer J Clin. 2018;68(6):394-424. https://doi.org/10.3322/caac.21492.

2. Herbst RS, Morgensztern D, Boshoff C. The biology and management of non-small cell lung cancer. Nature. 2018;553(7689):446-54. https://doi. org/10.1038/nature25183.

3. Wang S, Zimmermann S, Parikh K, Mansfield AS, Adjei AA. Current diagnosis and management of small-cell lung cancer. Mayo Clin Proc. 2019;94(8):1599-622. https://doi.org/10.1016/..mayocp.2019.01.034.

4. Klemm F, Joyce JA. Microenvironmental regulation of therapeutic response in cancer. Trends Cell Biol. 2015;25(4):198-213. https://doi.org/ 10.1016/j.tcb.2014.11.006.

5. Altorki NK, Markowitz GJ, Gao D, et al. The lung microenvironment: an important regulator of tumour growth and metastasis. Nat Rev Cancer. 2019;19(1):9-31. https://doi.org/10.1038/s41568-018-0081-9.

6. Wood SL, Pernemalm M, Crosbie PA, Whetton AD. The role of the tumor-microenvironment in lung cancer-metastasis and its relationship to potential therapeutic targets. Cancer Treat Rev. 2014;40(4):558-66. https://doi.org/10.1016/j.ctrv.2013.10.001.

7. Pontecorvi G, Bellenghi M, Puglisi R, Carè A, Mattia G. Tumor-derived extracellular vesicles and microRNAs: functional roles, diagnostic, prognostic and therapeutic options. Cytokine Growth Factor Rev. 2020;51:75-83. https://doi.org/10.1016/j.cytogfr.2019.12.010.

8. Sharma A, Johnson A. Exosome DNA: critical regulator of tumor immunity and a diagnostic biomarker. J Cell Physiol. 2020;235(3):1921-32. https://doi.org/10.1002/jcp.29153.

9. Krause HM. New and prospective roles for IncRNAs in organelle formation and function. Trends Genet. 2018;34(10):736-45. https://doi.org/10. 1016/j.tig.2018.06.005.

10. Choi DS, Kim DK, Kim YK, Gho YS. Proteomics, transcriptomics and lipidomics of exosomes and ectosomes. Proteomics. 2013;13(10-11):155471. https://doi.org/10.1002/pmic.201200329.

11. van Niel G, D'Angelo G, Raposo G. Shedding light on the cell biology of extracellular vesicles. Nat Rev Mol Cell Biol. 2018;19(4):213-28. https:// doi.org/10.1038/nrm.2017.125.

12. Ruiz-Martinez M, Navarro A, Marrades RM, et al. YKT6 expression, exosome release, and survival in non-small cell lung cancer. Oncotarget. 2016;7(32):51515-24. https://doi.org/10.18632/oncotarget.9862.

13. You J, Li M, Cao LM, et al. Snail1-dependent cancer-associated fibroblasts induce epithelial-mesenchymal transition in lung cancer cells via exosomes. QJM. 2019;112(8):581-90. https://doi.org/10.1093/qjmed/ hcZ093.

14. Duan S, Yu S, Yuan T, Yao S, Zhang L. Exogenous Let-7a-5p induces A549 lung cancer cell death through BCL2L1-mediated PI3Ky signaling pathway. Front Oncol. 2019;9:808. https://doi.org/10.3389/fonc.2019. 00808 (Published 2019 Aug 23). 
15. Zhang $X$, Sai B, Wang F, et al. Hypoxic BMSC-derived exosomal miRNAs promote metastasis of lung cancer cells via STAT3-induced EMT. Mol Cancer. 2019;18(1):40. https://doi.org/10.1186/s12943-019-0959-5 (Published 2019 Mar 13).

16. Xu ZH, Miao ZW, Jiang QZ, et al. Brain microvascular endothelial cell exosome-mediated S100A16 up-regulation confers small-cell lung cancer cell survival in brain. FASEB J. 2019;33(2):1742-57. https://doi. org/10.1096/f. $201800428 R$.

17. DeVito NC, Plebanek MP, Theivanthiran B, Hanks BA. Role of tumormediated dendritic cell tolerization in immune evasion. Front Immunol. 2019;10:2876. https://doi.org/10.3389/fimmu.2019.02876 (Published 2019 Dec 10).

18. Montecalvo A, Larregina AT, Shufesky WJ, et al. Mechanism of transfer of functional microRNAs between mouse dendritic cells via exosomes. Blood. 2012;119(3):756-66. https://doi.org/10.1182/ blood-2011-02-338004.

19. Yin W, Ouyang S, Li Y, Xiao B, Yang H. Immature dendritic cell-derived exosomes: a promise subcellular vaccine for autoimmunity published correction appears in [published correction appears in Inflammation. 2013 Feb;36(1):241]. Inflammation. 2013;36(1):232-40. https://doi.org/ 10.1007/s10753-012-9539-1.

20. Zhang F, Li R, Yang Y, et al. Specific decrease in B-cell-derived extracellular vesicles enhances post-chemotherapeutic $\mathrm{CD} 8^{+} \mathrm{T}$ cell responses. Immunity. 2019;50(3):738-50. https://doi.org/10.1016/j.immuni.2019.01. 010.

21. Fu W, Lei C, Liu S, et al. CAR exosomes derived from effector CAR-T cells have potent antitumour effects and low toxicity. Nat Commun. 2019;10(1):4355. https://doi.org/10.1038/s41467-019-12321-3 (Published 2019 Sep 25).

22. Saunderson SC, Dunn AC, Crocker PR, McLellan AD. CD169 mediates the capture of exosomes in spleen and lymph node. Blood. 2014;123(2):208-16. https://doi.org/10.1182/blood-2013-03-489732.

23. Miyanishi M, Tada K, Koike M, Uchiyama Y, Kitamura T, Nagata S. Identification of Tim4 as a phosphatidylserine receptor. Nature. 2007:450(7168):435-9. https://doi.org/10.1038/nature06307.

24. Chen T, Guo J, Yang M, Zhu X, Cao X. Chemokine-containing exosomes are released from heat-stressed tumor cells via lipid raftdependent pathway and act as efficient tumor vaccine. I Immunol. 2011;186(4):2219-28. https://doi.org/10.4049/jimmunol.1002991.

25. Mulcahy LA, Pink RC, Carter DR. Routes and mechanisms of extracellular vesicle uptake. J Extracell Vesicles. 2014. https://doi.org/10.3402/jev.v3. 24641 (Published 2014 Aug 4.)

26. Gonda A, Kabagwira J, Senthil GN, Wall NR. Internalization of exosomes through receptor-mediated endocytosis. Mol Cancer Res. 2019;17(2):337-47. https://doi.org/10.1158/1541-7786.MCR-18-0891.

27. Fabbri M, Paone A, Calore F, et al. MicroRNAs bind to Toll-like receptors to induce prometastatic inflammatory response. Proc Natl Acad Sci USA. 2012;109(31):E2110-6. https://doi.org/10.1073/pnas.1209414109.

28. Horibe S, Tanahashi T, Kawauchi S, Murakami Y, Rikitake Y. Mechanism of recipient cell-dependent differences in exosome uptake. BMC Cancer. 2018;18(1):47. https://doi.org/10.1186/s12885-017-3958-1 (Published 2018 Jan 6).

29. Liu M, Tong Z, Ding C, et al. Transcription factor c-Maf is a checkpoint that programs macrophages in lung cancer. J Clin Invest. 2020;130(4):2081-96. https://doi.org/10.1172/JCl131335.

30. Essandoh K, Li Y, Huo J, Fan GC. MiRNA-mediated macrophage polarization and its potential role in the regulation of inflammatory response. Shock. 2016;46(2):122-31. https://doi.org/10.1097/SHK.0000000000 000604.

31. Pritchard A, Tousif S, Wang Y, et al. Lung tumor cell-drived exosomes promote M2 macrophage polarization. Cells. 2020;9(5):1303. https://doi. org/10.3390/cells9051303.

32. Park JE, Dutta B, Tse SW, et al. Hypoxia-induced tumor exosomes promote M2-like macrophage polarization of infiltrating myeloid cells and microRNA-mediated metabolic shift. Oncogene. 2019;38(26):5158-73. https://doi.org/10.1038/s41388-019-0782-x.

33. Hsu YL, Hung JY, Chang WA, et al. Hypoxic lung-cancer-derived extracellular vesicle microRNA-103a increases the oncogenic effects of macrophages by targeting PTEN. Mol Ther. 2018;26(2):568-81. https:// doi.org/10.1016/j.ymthe.2017.11.016.
34. Trivedi M, Talekar M, Shah P, et al. Modification of tumor cell exosome content by transfection with wt-p53 and microRNA-125b expressing plasmid DNA and its effect on macrophage polarization. Oncogenesis. 2016;5(8):e250. https://doi.org/10.1038/oncsis.2016.52.

35. Topalian SL, Weiner GJ, Pardoll DM. Cancer immunotherapy comes of age. J Clin Oncol. 2011;29(36):4828-36. https://doi.org/10.1200/JCO. 2011.38.0899.

36. Pitt JM, Charrier M, Viaud S, et al. Dendritic cell-derived exosomes as immunotherapies in the fight against cancer. J Immunol. 2014;193(3):1006-11. https://doi.org/10.4049/jimmunol.1400703.

37. Wang C, Huang X, Wu Y, Wang J, Li F, Guo G. Tumor Cell-associated exosomes robustly elicit anti-tumor immune responses through modulating dendritic cell vaccines in lung tumor. Int J Biol Sci. 2020;16(4):633-43. https://doi.org/10.7150/ijbs.38414 (Published 2020 Jan 14).

38. André F, Chaput N, Schartz NE, et al. Exosomes as potent cell-free peptide-based vaccine. I. Dendritic cell-derived exosomes transfer functional MHC class I/peptide complexes to dendritic cells. J Immunol. 2004;172(4):2126-36. https://doi.org/10.4049/jimmunol.172.4. 2126.

39. Théry $C$, Duban $L$, Segura E, Véron $P$, Lantz O, Amigorena S. Indirect activation of naive $C D 4+T$ cells by dendritic cell-derived exosomes. Nat Immunol. 2002;3(12):1156-62. https://doi.org/10.1038/ni854.

40. Li W, Mu D, Tian F, et al. Exosomes derived from Rab27a-overexpressing tumor cells elicit efficient induction of antitumor immunity. Mol Med Rep. 2013;8(6):1876-82. https://doi.org/10.3892/mmr.2013.1738.

41. Kiessling R, Klein E, Pross H, Wigzell H. "Natural" killer cells in the mouse. II. Cytotoxic cells with specificity for mouse Moloney leukemia cells. Characteristics of the killer cell. Eur J Immunol. 1975;5(2):117-21. https://doi.org/10.1002/eji.1830050209.

42. Jin S, Deng Y, Hao JW, et al. NK cell phenotypic modulation in lung cancer environment. PLoS ONE. 2014;9(10):e109976. https://doi.org/ 10.1371/journal.pone.0109976 (Published 2014 Oct 9).

43. Lv LH, Wan YL, Lin Y, et al. Anticancer drugs cause release of exosomes with heat shock proteins from human hepatocellular carcinoma cells that elicit effective natural killer cell antitumor responses in vitro. J Biol Chem. 2012;287(19):15874-85. https://doi.org/10.1074/ jbc.M112.340588.

44. Berchem G, Noman MZ, Bosseler M, et al. Hypoxic tumor-derived microvesicles negatively regulate NK cell function by a mechanism involving TGF- $\beta$ and miR23a transfer. Oncoimmunology. 2015;5(4):e1062968. https://doi.org/10.1080/2162402X.2015.1062968 (Published 2015 Jun 24).

45. Quatrini L, Molfetta R, Zitti B, et al. Ubiquitin-dependent endocytosis of NKG2D-DAP10 receptor complexes activates signaling and functions in human NK cells. Sci Signal. 2015;8(400):ra108. https://doi.org/ 10.1126/scisignal.aab2724 (Published 2015 Oct 27).

46. Vulpis E, Soriani A, Cerboni C, Santoni A, Zingoni A. Cancer exosomes as conveyors of stress-induced molecules: new players in the modulation of NK cell response. Int J Mol Sci. 2019;20(3):611. https://doi. org/10.3390/ijms20030611 (Published 2019 Jan 31)

47. Di Pace AL, Tumino N, Besi F, et al. Characterization of human NK cellderived exosomes: role of DNAM1 receptor in exosome-mediated cytotoxicity against tumor. Cancers. 2020;12(3):661. https://doi.org/ 10.3390/cancers12030661 (Published 2020 Mar 12).

48. Peng J, Yu Z, Xue L, et al. The effect of foxp3-overexpressing Treg cells on non-small cell lung cancer cells. Mol Med Rep. 2018;17(4):5860-8. https://doi.org/10.3892/mmr.2018.8606.

49. Ning $Y$, Shen $K$, Wu Q, et al. Tumor exosomes block dendritic cells maturation to decrease the T cell immune response. Immunol Lett. 2018;199:36-43. https://doi.org/10.1016/j.imlet.2018.05.002.

50. Chen G, Huang AC, Zhang W, et al. Exosomal PD-L1 contributes to immunosuppression and is associated with anti-PD-1 response. Nature. 2018;560(7718):382-6. https://doi.org/10.1038/ s41586-018-0392-8.

51. Poggio M, HuT, Pai CC, et al. Suppression of exosomal PD-L1 induces systemic anti-tumor immunity and memory. Cell. 2019;177(2):414-427. e13. https://doi.org/10.1016/j.cell.2019.02.016.

52. Luchini C, Bibeau F, Ligtenberg MJL, et al. ESMO recommendations on microsatellite instability testing for immunotherapy in cancer, and its relationship with PD-1/PD-L1 expression and tumour 
mutational burden: a systematic review-based approach. Ann Oncol. 2019;30(8):1232-43. https://doi.org/10.1093/annonc/mdz1 16.

53. Okoye IS, Coomes SM, Pelly VS, et al. MicroRNA-containing T-regulatorycell-derived exosomes suppress pathogenic T helper 1 cells. Immunity. 2014;41(1):89-103. https://doi.org/10.1016/j.immuni.2014.05.019.

54. Huang SH, Li Y, Zhang J, Rong J, Ye S. Epidermal growth factor receptorcontaining exosomes induce tumor-specific regulatory T cells. Cancer Invest. 2013;31(5):330-5. https://doi.org/10.3109/07357907.2013. 789905.

55. Park JH, Ko JS, Shin Y, et al. Intranuclear interactomic inhibition of FoxP3 suppresses functions of Treg cells [published correction appears in Biochem Biophys Res Commun. 2014 Sep 12;452(1):205. Bothwell, Alfred M [corrected to Bothwell, Alfred L M]]. Biochem Biophys Res Commun. 2014;451(1):1-7. doi:https://doi.org/10.1016/j.bbrc.2014.06.141

56. Kalvala A, Wallet P, Yang L, et al. Phenotypic switching of Naïve T cells to immune-suppressive treg-like cells by mutant KRAS. J Clin Med. 2019:8(10):1726. https://doi.org/10.3390/jcm8101726 (Published 2019 Oct 18)

57. Azuma H, Yoshida Y, Takahashi H, et al. Liposomal microparticle injection can induce myeloid-derived suppressor cells (MDSC)-like cells in vivo. Immunopharmacol Immunotoxicol. 2017;39(3):140-7. https:// doi.org/10.1080/08923973.2017.1306867.

58. Bayne $\sqcup$, Beatty $G L$, Jhala N, et al. Tumor-derived granulocyte-macrophage colony-stimulating factor regulates myeloid inflammation and T cell immunity in pancreatic cancer. Cancer Cell. 2012;21(6):822-35. https://doi.org/10.1016/j.ccr.2012.04.025.

59. Xiang X, Poliakov A, Liu C, et al. Induction of myeloid-derived suppressor cells by tumor exosomes. Int J Cancer. 2009;124(11):2621-33. https://doi.org/10.1002/ijc.24249.

60. Ridder K, Sevko A, Heide J, et al. Extracellular vesicle-mediated transfer of functional RNA in the tumor microenvironment. Oncoimmunology. 2015;4(6):e1008371. https://doi.org/10.1080/2162402X.2015.1008371 (Published 2015 Mar 19).

61. Lamouille S, Xu J, Derynck R. Molecular mechanisms of epithelial-mesenchymal transition. Nat Rev Mol Cell Biol. 2014;15(3):178-96. https:// doi.org/10.1038/nrm3758.

62. You J, Li M, Tan Y, et al. Snail 1-expressing cancer-associated fibroblasts induce lung cancer cell epithelial-mesenchymal transition through miR-33b. Oncotarget. 2017;8(70):114769-86. https://doi.org/10.18632/ oncotarget.23082 (Published 2017 Dec 7).

63. Lobb RJ, van Amerongen R, Wiegmans A, Ham S, Larsen JE, Möller A. Exosomes derived from mesenchymal non-small cell lung cancer cells promote chemoresistance. Int J Cancer. 2017;141(3):614-20. https://doi. org/10.1002/ijc.30752

64. He S, Li Z, Yu Y, et al. Exosomal miR-499a-5p promotes cell proliferation, migration and EMT via mTOR signaling pathway in lung adenocarcinoma. Exp Cell Res. 2019;379(2):203-13. https://doi.org/10.1016/j.yexcr. 2019.03.035.

65. Zhuang G, Wu X, Jiang Z, et al. Tumour-secreted miR-9 promotes endothelial cell migration and angiogenesis by activating the JAK-STAT pathway. EMBO J. 2012;31(17):3513-23. https://doi.org/10.1038/emboj. 2012.183.

66. Lawson J, Dickman C, Towle R, Jabalee J, Javer A, Garnis C. Extracellular vesicle secretion of miR-142-3p from lung adenocarcinoma cells induces tumor promoting changes in the stroma through cell-cell communication. Mol Carcinog. 2019;58(3):376-87. https://doi.org/10. 1002/mc.22935.

67. Gangoda L, Boukouris S, Liem M, Kalra H, Mathivanan S. Extracellular vesicles including exosomes are mediators of signal transduction: are they protective or pathogenic? Proteomics. 2015;15(2-3):260-71. https://doi.org/10.1002/pmic.201400234.

68. Fan J, Xu G, Chang Z, Zhu L, Yao J. miR-210 transferred by lung cancer cell-derived exosomes may act as proangiogenic factor in cancerassociated fibroblasts by modulating JAK2/STAT3 pathway. Clin Sci. 2020;134(7):807-25. https://doi.org/10.1042/CS20200039.

69. Costa-Silva B, Aiello NM, Ocean AJ, et al. Pancreatic cancer exosomes initiate pre-metastatic niche formation in the liver. Nat Cell Biol. 2015;17(6):816-26. https://doi.org/10.1038/ncb3169.

70. Simons M, Raposo G. Exosomes-vesicular carriers for intercellular communication. Curr Opin Cell Biol. 2009;21(4):575-81. https://doi.org/10. 1016/j.ceb.2009.03.007.
71. Zhao H, Yang L, Baddour J, et al. Tumor microenvironment derived exosomes pleiotropically modulate cancer cell metabolism. Elife. 2016;5:e10250. https://doi.org/10.7554/eLife.10250 (Published 2016 Feb 27).

72. Jaiswal RK, Kumar P, Yadava PK. Telomerase and its extracurricular activities. Cell Mol Biol Lett. 2013;18(4):538-54. https://doi.org/10.2478/ s11658-013-0105-0.

73. Hoffman RM. Stromal-cell and cancer-cell exosomes leading the metastatic exodus for the promised niche. Breast Cancer Res. 2013;15(3):310. https://doi.org/10.1186/bcr3426 (Published 2013 Jun 18).

74. Gutkin A, Uziel O, Beery E, et al. Tumor cells derived exosomes contain hTERT mRNA and transform nonmalignant fibroblasts into telomerase positive cells. Oncotarget. 2016;7(37):59173-88. https://doi.org/10. 18632/oncotarget.10384.

75. Kohlhapp FJ, Mitra AK, Lengyel E, Peter ME. MicroRNAs as mediators and communicators between cancer cells and the tumor microenvironment. Oncogene. 2015;34(48):5857-68. https://doi.org/10.1038/onc. 2015.89.

76. Hsu YL, Hung JY, Chang WA, et al. Hypoxic lung cancer-secreted exosomal miR-23a increased angiogenesis and vascular permeability by targeting prolyl hydroxylase and tight junction protein ZO-1. Oncogene. 2017;36(34):4929-42. https://doi.org/10.1038/onc.2017.105.

77. Mo F, Xu Y, Zhang J, et al. Effects of hypoxia and radiation-induced exosomes on migration of lung cancer cells and angiogenesis of umbilical vein endothelial cells. Radiat Res. 2020. https://doi.org/10. 1667/RR15555.1 (published online ahead of print, 2020 Apr 30).

78. Cui H, Seubert B, Stahl E, et al. Tissue inhibitor of metalloproteinases-1 induces a pro-tumourigenic increase of miR-210 in lung adenocarcinoma cells and their exosomes. Oncogene. 2015;34(28):3640-50. https://doi.org/10.1038/onc.2014.300.

79. Liu Y, Luo F, Wang B, et al. STAT3-regulated exosomal miR-21 promotes angiogenesis and is involved in neoplastic processes of transformed human bronchial epithelial cells. Cancer Lett. 2016;370(1):125-35. https://doi.org/10.1016/j.canlet.2015.10.011.

80. Jeong K, Yu YJ, You JY, Rhee WJ, Kim JA. Exosome-mediated microRNA-497 delivery for anti-cancer therapy in a microfluidic 3D lung cancer model. Lab Chip. 2020;20(3):548-57. https://doi.org/10.1039/ c9lc00958b.

81. Liu Y, Gu Y, Han Y, et al. Tumor exosomal RNAs promote lung premetastatic Niche formation by activating alveolar epithelial TLR3 to recruit neutrophils. Cancer Cell. 2016;30(2):243-56. https://doi.org/10. 1016/..ccell.2016.06.021

82. Syed V. TGF- $\beta$ signaling in cancer. J Cell Biochem. 2016;117(6):1279-87. https://doi.org/10.1002/jcb.25496.

83. Li L, Yang $L$, Wang $L$, et al. Impaired $T$ cell function in malignant pleural effusion is caused by TGF- $\beta$ derived predominantly from macrophages. Int J Cancer. 2016;139(10):2261-9. https://doi.org/10.1002/ijc.30289.

84. Wu DM, Deng SH, Liu T, Han R, Zhang T, Xu Y. TGF- $\beta$-mediated exosomal Inc-MMP2-2 regulates migration and invasion of lung cancer cells to the vasculature by promoting MMP2 expression [published correction appears in Cancer Med. $2020 \mathrm{Jul} ; 9(13): 4876]$. Cancer Med. 2018;7(10):5118-29. https://doi.org/10.1002/cam4.1758.

85. Wood LW, Cox NI, Phelps CA, et al. Thyroid Transcription Factor 1 Reprograms Angiogenic Activities of Secretome. Sci Rep. 2016;6:19857. https://doi.org/10.1038/srep19857 (Published 2016 Feb 25).

86. Li Z, Zeng C, Nong Q, et al. Exosomal Leucine-Rich-Alpha2-Glycoprotein 1 Derived from Non-Small-Cell Lung Cancer Cells Promotes Angiogenesis via TGF- $\beta$ Signal Pathway. Mol Ther Oncolytics. 2019;14:313-322. Published 2019 Aug 7. doi:https://doi.org/10.1016/j.omto.2019.08.001

87. Yang F, Yan Y, Yang Y, et al. MiR-210 in exosomes derived from CAFs promotes non-small cell lung cancer migration and invasion through PTEN/PI3K/AKT pathway. Cell Signal. 2020;73:109675. https://doi.org/10 1016/j.cellsig.2020.109675.

88. Hu YF, Cui J, Jin L, et al. LRPPRC contributes to the cisplatin resistance of lung cancer cells by regulating MDR1 expression. Oncol Rep. 2021;45(4):4. https://doi.org/10.3892/or.2021.7955.

89. Qin X, Yu S, Zhou L, et al. Cisplatin-resistant lung cancer cell-derived exosomes increase cisplatin resistance of recipient cells in exosomal miR-100-5p-dependent manner. Int J Nanomedicine. 2017;12:3721-33. https://doi.org/10.2147/IJN.S131516 (Published 2017 May 15). 
90. Wei F, Ma C, Zhou T, et al. Exosomes derived from gemcitabine-resistant cells transfer malignant phenotypic traits via delivery of miRNA-222-3p. Mol Cancer. 2017;16(1):132. https://doi.org/10.1186/s12943-017-0694-8 (Published 2017 Jul 25).

91. Tang Y, Cui Y, Li Z, et al. Radiation-induced miR-208a increases the proliferation and radioresistance by targeting p21 in human lung cancer cell [published correction appears in J Exp Clin Cancer Res. 2016;35:20, Cheng, Guangxia [corrected to Chen, Guangxia]]. J Exp Clin Cancer Res. 2016;35:7. https://doi.org/10.1186/s13046-016-0285-3.

92. Koo T, Cho BJ, Kim DH, et al. MicroRNA-200c increases radiosensitivity of human cancer cells with activated EGFR-associated signaling. Oncotarget. 2017;8(39):65457-68. https://doi.org/10.18632/oncotarget. 18924 (Published 2017 Jul 3).

93. Luo H, Liang C. MicroRNA-148b inhibits proliferation and the epithelialmesenchymal transition and increases radiosensitivity in non-small cell lung carcinomas by regulating ROCK1. Exp Ther Med. 2018;15(4):360916. https://doi.org/10.3892/etm.2018.5845.

94. Wu H, Zhou J, Mei S, et al. Circulating exosomal microRNA-96 promotes cell proliferation, migration and drug resistance by targeting LMO7. J Cell Mol Med. 2017;21 (6):1228-36. https://doi.org/10.1111/jcmm.13056.

95. Zhou J, Kwak KJ, Wu Z, et al. PLAUR Confers Resistance to Gefitinib Through EGFR/P-AKT/Survivin Signaling Pathway. Cell Physiol Biochem. 2018;47(5):1909-24. https://doi.org/10.1159/000491071.

96. Azuma Y, Yokobori T, Mogi A, et al. Cancer exosomal microRNAs from gefitinib-resistant lung cancer cells cause therapeutic resistance in gefitinib-sensitive cells. Surg Today. 2020. https://doi.org/10.1007/ s00595-020-01976-x (published online ahead of print, 2020 Feb 12).

97. Zhang W, Cai X, Yu J, Lu X, Qian Q, Qian W. Exosome-mediated transfer of IncRNA RP11-838N2.4 promotes erlotinib resistance in non-small cell lung cancer. Int J Oncol. 2018;53(2):527-38. https://doi.org/10.3892/ijo. 2018.4412.

98. Pan R, Zhou H. Exosomal transfer of IncRNA H19 promotes erlotinib resistance in non-small cell lung cancer via miR-615-3p/ATG7 Axis. Cancer Manag Res. 2020;12:4283-97. https://doi.org/10.2147/CMAR.S2410 95 (Published 2020 Jun 8)

99. Wang LK, Pan SH, Chang YL, et al. MDA-9/Syntenin-Slug transcriptional complex promote epithelial-mesenchymal transition and invasion/ metastasis in lung adenocarcinoma. Oncotarget. 2016;7(1):386-401. https://doi.org/10.18632/oncotarget.6299.

100. Kim DH, Park S, Kim H, et al. Tumor-derived exosomal miR-619-5p promotes tumor angiogenesis and metastasis through the inhibition of RCAN1.4. Cancer Lett. 2020;475:2-13. https://doi.org/10.1016/j.canlet. 2020.01.023.

101. Yamashita T, Kamada H, Kanasaki S, et al. Epidermal growth factor receptor localized to exosome membranes as a possible biomarker for lung cancer diagnosis. Pharmazie. 2013;68(12):969-73.

102. Hang L, Hao C, Zhai R, et al. Downregulation of exosomal let-7a-5p in dust exposed- workers contributes to lung cancer development. Respir Res. 2018;19(1):235. https://doi.org/10.1186/s12931-018-0949-y (Published 2018 Nov 29)

103. Bica-Pop C, Cojocneanu-Petric R, Magdo L, Raduly L, Gulei D, BerindanNeagoe I. Overview upon miR-21 in lung cancer: focus on NSCLC. Cell Mol Life Sci. 2018;75(19):3539-51. https://doi.org/10.1007/ s00018-018-2877-X.

104. Sun $\mathrm{S}$, Chen $\mathrm{H}$, Xu C, et al. Exosomal miR-106b serves as a novel marker for lung cancer and promotes cancer metastasis via targeting PTEN. Life Sci. 2020;244:117297. https://doi.org/10.1016/j.lfs.2020.117297.

105. $\mathrm{Hu} \mathrm{H}, \mathrm{Xu} \mathrm{H}$, Lu F, et al. Exosome-derived miR-486-5p regulates cell cycle, proliferation and metastasis in lung adenocarcinoma via targeting NEK2. Front Bioeng Biotechnol. 2020;8:259. https://doi.org/10.3389/ fbioe.2020.00259 (Published 2020 Apr 8).

106. Castellanos-Rizaldos E, Zhang X, Tadigotla VR, et al. Exosome-based detection of activating and resistance EGFR mutations from plasma of non-small cell lung cancer patients. Oncotarget. 2019;10(30):2911-20. https://doi.org/10.18632/oncotarget.26885 (Published 2019 Apr 23).
107. Castellanos-Rizaldos E, Grimm DG, Tadigotla V, et al. Exosome-based detection of EGFR T790M in plasma from non-small cell lung cancer patients. Clin Cancer Res. 2018;24(12):2944-50. https://doi.org/10.1158/ 1078-0432.CCR-17-3369.

108. Mlika M, Dziri C, Zorgati MM, et al. Liquid biopsy as surrogate to tissue in lung cancer for molecular profiling: a meta-analysis. Curr Respir Med Rev. 2018;14(1):48-60. https://doi.org/10.2174/1573398X146661804301 44452.

109. Ilié M, Hofman P. Pros: Can tissue biopsy be replaced by liquid biopsy? TransI Lung Cancer Res. 2016;5(4):420-3. https://doi.org/10.21037/t|cr. 2016.08.06.

110. Xu QL, Ye L, Huang LT, et al. Serum exosomal miRNA might be a novel liquid biopsy to identify leptomeningeal metastasis in non-small cell lung cancer. Onco Targets Ther. 2021;14:2327-35. https://doi.org/10. 2147/OTT.S291611.eCollection2021.

111. Zhang Y, Zhang YM, Yin YH, et al. Detection of circulating exosomal miR17-5p serves as a novel non-invasive diagnostic marker for non-small cell lung cancer patients. Pathol Res Pract. 2019;215(8):152466. https:// doi.org/10.1016/j.prp.2019.152466.

112. Choi ES, Faruque HA, Kim KJ, et al. CD5L as an extracellular vesiclederived biomarker for liquid biopsy of lung cancer. Diagnostics. 2021;11(4):620. https://doi.org/10.3390/diagnostics11040620.

113. Yang YL, Hu ZX, Zhou YC, et al. The clinical use of circulating microRNAs as non-invasive diagnostic biomarkers for lung cancers. Oncotarget. 2017;8(52):90197-214. https://doi.org/10.18632/oncotarget.21644.

114. Krug AK, Enderle D, Karlovich C, et al. Improved EGFR mutation detection using combined exosomal RNA and circulating tumor DNA in NSCLC patient plasma. Ann Oncol. 2018;29(3):700-6. https://doi.org/10. 1093/annonc/mdx765.

115. Rijavec E, Coco S, Genova C, et al. Liquid biopsy in non-small cell lung cancer: highlights and challenges. Cancer. 2019;12(1):17. https://doi. org/10.3390/cancers12010017.

116. Shimada Y, Matsubayashi J, Kudo Y, et al. Serum-derived exosomal PD-L1 expression to predict anti-PD-1 response and in patients with non-small cell lung cancer. Sci Rep. 2021;11(1):7830. https://doi.org/10. 1038/s41598-021-87575-3.

117. Le DT, Durham JN, Smith KN. Mismatch repair deficiency predicts response of solid tumors to PD-1 blockade. Science. 2017;357(6349):409-13. https://doi.org/10.1126/science.aan6733.

118. Ma J, Wang PL, Huang L, et al. Bioinformatic analysis reveals an exosomal miRNA-mRNA network in colorectal cancer. BMC Med Genomics. 2021:14(1):60. https://doi.org/10.1186/s12920-021-00905-2.

119. Hunag CL, Liu ST, Tong $X$, et al. Extracellular vesicles and ctDNA in lung cancer: biomarker sourcesand therapeutic applications. Cancer Chemother Pharmacol. 2018;82(2):171-83. https://doi.org/10.1007/ s00280-018-3586-8.

120. Al-Nedawi K, Meehan B, Kerbel RS, Allison AC, Rak J. Endothelial expression of autocrine VEGF upon the uptake of tumor-derived microvesicles containing oncogenic EGFR. Proc Natl Acad Sci U S A. 2009;106(10):3794-9. https://doi.org/10.1073/pnas.0804543106.

121. Rahman MA, Barger JF, Lovat F, Gao M, Otterson GA, Nana-Sinkam P. Lung cancer exosomes as drivers of epithelial mesenchymal transition. Oncotarget. 2016;7(34):54852-66. https://doi.org/10.18632/oncotarget. 10243.

122. Liu Q, Xiang Y, Yuan S, et al. Plasma exosome levels in non-small-cell lung cancer: correlation with clinicopathological features and prognostic implications. Cancer Biomark. 2018;22(2):267-74. https://doi.org/10. 3233/CBM-170955.

\section{Publisher's Note}

Springer Nature remains neutral with regard to jurisdictional claims in published maps and institutional affiliations. 